\title{
Entrevista
}

Imagen y memoria: de la vida cotidiana a la galería

Entrevista a la fotógrafa Paola Ismene

"Image and Memory: from Daily Life to the Gallery"

Interview with photographer Paola Ismene

Valeria Sánchez Michel

Universidad Iberoamericana Ciudad de México

Hay fotografías QUe, aL MOMENTO de ESTAR FRENTE a ELLAS, NOS REgRESAN FRAGmentos de nuestra propia experiencia. El estar ante las imágenes de Paola Ismene es detenerse y contemplar la vida diaria para descubrir colores, patrones, formas y elementos que generalmente pasan desapercibidos o que no nos detenemos a reparar en ellos. Ella es una fotógrafa emergente, quien ha expresado que sus fotos surgen de una constante necesidad de resignificar lo cotidiano.

Paola Ismene nació y vive en la Ciudad de México, estudió Comunicación en la Universidad Nacional Autónoma de México y comenzó su formación como fotógrafa en la Escuela Activa de Fotografía. Ha recibido varios premios, entre los que podemos destacar el obtenido en julio de 2021 en la categoría de "Environmental Portrait" de los Documentary Family Awards (DFA); ${ }^{1}$ fue finalista en 2020 de la Beca Photo Taken de la Lucie Foundation y ganó el concurso \#SelfExpression de la galería Saatchi de Londres en 2017. Su trabajo ha formado parte de exposiciones en España, Italia, Inglaterra y, por supuesto, en México.

1 Para quienes nos dedicamos al estudio y análisis de la fotografía, los premios de la DFA ofrecen una oportunidad única para acercarse a la forma en que su jurado delibera sobre las imágenes, pues la ronda final de discusión del jurado es transmitida en vivo a través de Internet. Así, los espectadores pueden presenciar las discusiones y los debates que sostienen fotógrafos, fotoperiodistas y editores. 
Nierika 21 - Año 11 - enero-junio de 2022

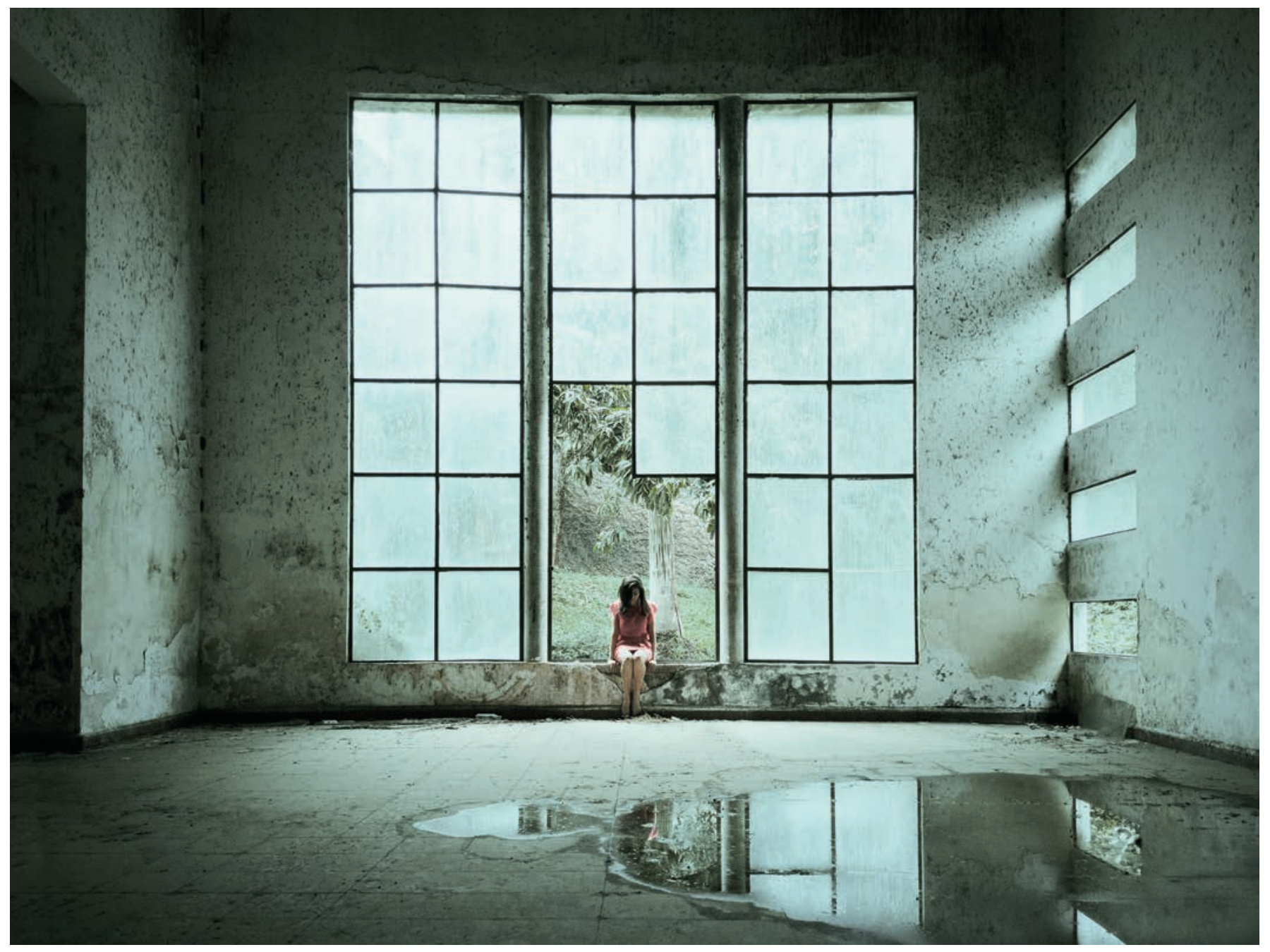

Figura 1. Paola Ismene, Duelo (2019). Fotografía digital. 
Las series, ensayos y fotos que conforman el trabajo de Paola Ismene juegan entre capturar la realidad, la construcción de memoria (de su memoria) e imágenes oníricas. Las preguntas que le planteé en esta entrevista buscan indagar sobre la forma en que conceptualiza y construye sus proyectos y sus fotos. En esta ocasión, el intercambio fue por correo electrónico, lo cual le permitió a ella tener tiempo para meditar de una manera especial sus respuestas.

Valeria Sánchez Michel (VSM): Paola, muchas gracias por aceptar esta entrevista, por permitirme dialogar contigo sobre tu trabajo como fotógrafa. Nunca deja de sorprenderme tu capacidad de capturar imágenes de la vida cotidiana que le son a uno familiares $y$, al mismo tiempo, permites que uno se detenga en ellas y pueda descubrir otra forma de apreciar esas escenas. Considero que una característica de tu trabajo es el manejo del color, con una cromática donde hay ciertas tonalidades (como el verde y el rosa pálido) que suelen prevalecer. Pero dime, ¿cómo describirías, de forma general y en tus palabras, tu trabajo?

Paola Ismene (PI): La fotografía es mi principal forma de expresión y además me obliga a estar presente. Mi trabajo surge a partir de una necesidad personal de significar lo cotidiano. A través de procesos introspectivos intento construir narrativas que juegan entre lo real y lo imaginario, en busca de una identificación colectiva. Me interesa explorar la complejidad de las emociones humanas y vincularlas al espacio físico. El color juega un papel muy importante dentro de mis fotografías ya que me permite jugar con la imagen, darle un aspecto un poco más onírico o surreal.

vsm: Estudiaste Ciencias de la Comunicación en la UNAM y después comenzaste tu formación como fotógrafa en la Escuela Activa de Fotografía. ¿Cómo llegaste a la fotografía?

PI: Entré a la licenciatura en Ciencias de la Comunicación porque deseaba estudiar algo relacionado con el cine y en su momento me pareció lo más 
cercano. En la carrera me di cuenta que no era lo que me gustaba, por las áreas en las que estaba enfocada la carrera en Ciudad Universitaria, me sentía bastante perdida. En séptimo semestre decidí tomar la materia optativa de Fotografía y por fin encontré algo que me hacía sentir motivada y con ganas de aprender. Podía expresarme fácilmente: me la pasaba haciendo fotos sin parar. Mi profesora notó la facilidad que tenía con el medio y me impulsó a seguir aprendiendo y mejorando mi técnica. Tomé otras dos materias relacionadas con fotografía en la facultad y al terminar la carrera decidí entrar a la Escuela Activa de Fotografía para poder profesionalizar mis estudios en el área.

vsm: Para algunos investigadores la cámara análoga representa también un reto técnico. El salto a la cámara digital ha sido bienvenido por algunos fotógrafos y denostado por otros. Tú has optado, además, por crear imágenes con el teléfono, cuando para muchos las imágenes que estos aparatos producen sólo sirven como registro, o son propias de aficionados... ¿Por qué optar por la fotografía con celular?

PI: Aprendí fotografía con una cámara análoga, lo que me dio las bases en cuanto a mi forma de observar, entender la luz, aprender el funcionamiento de una cámara y, sobre todo, pensar muy bien lo que iba a fotografiar, ya que cada "tiro" costaba, pues todo el material para revelar comenzaba a ser muy costoso. Por esa razón compré mi primera cámara digital. Mi acercamiento a la fotografía móvil fue bastante circunstancial ya que debido a situaciones personales tuve que dejar por un tiempo la carrera y mi trabajo de fotografía, así que comencé a hacer imágenes con mi celular sobre lo que estaba viviendo y de mi cotidianidad en general; me parecía muy práctico porque el teléfono es algo que cargas para todos lados y era más seguro que andar por la ciudad con una cámara profesional. Sin buscarlo realmente, poco a poco se convirtió en una de mis principales herramientas de trabajo. Actualmente la tecnología ha evolucionado mucho con la calidad de las cámaras en los teléfonos, así que ya es casi lo mismo que traer una cámara digital. Para mí, el formato nada tiene que ver con el mensaje, usar un teléfono celular para fotografiar simplemente fue algo 
que surgió debido a su practicidad y no diferencia en nada la calidad de mis proyectos, pues no define su contenido.

vsm: Cuando se consulta tu página web, ${ }^{2}$ uno se encuentra con que divides tu trabajo en "proyectos" y "relatos". ¿Cuál es la diferencia entre unos y otros?

PI: Los "proyectos" los llevo a cabo a partir de una idea o tema que me interesa trabajar. Realizo una investigación previa, hago bocetos, busco locaciones; es decir, tienen un desarrollo más complejo y, por lo tanto, requieren de mayor tiempo. Por otra parte, los "relatos" son viajes o vivencias personales que fotografío de manera espontánea como parte de mi cotidianidad, pero que a su vez se convierten en un relato que deseo compartir.

vSM: En algunas ocasiones recurres al formato de video. ¿Cuándo decides optar por este medio? ¿Cómo complementa éste tu trabajo fotográfico?

PI: Conforme fui desarrollando mis proyectos noté que con la foto estática a veces me sentía limitada para transmitir lo que deseaba, por lo que comencé a incorporar el video en mi trabajo con las bases que había aprendido durante la carrera. Es un medio que me interesa explorar mucho más, ya que siento que aún me cuesta trabajo desenvolverme y dejar de pensar sólo en la imagen fija.

vsm: En 2017 ganaste la categoría Autorretrato en los Mobile Photography Awards. ¿Cuál es el proceso creativo en la construcción de ese autorretrato? En la imagen te encuentras en pie sobre rocas, en medio de la imagen, dando la espalda al espectador, con ríos de agua a tu alrededor, rocas y bosque de fondo.

PI: Los autorretratos juegan un papel fundamental en mi trabajo. Comencé a realizarlos a partir de una necesidad personal de expresión y se han vuelto un elemento primordial de algunos proyectos. Los llevo a cabo de

2 https://www.paolaismene.com. 
diferentes maneras, algunas veces son algo que no planeo, simplemente estoy en un lugar o situación que llaman mi atención y los realizo. Otras ocasiones son escenas que pienso previamente. El que describes, por ejemplo, es parte de un proyecto que surge a partir de un diario de sueños que realicé durante aproximadamente un año, en el cual hubo preparación y exploración previos. Mi idea al mostrarme de espaldas es para que cualquiera pueda identificarse con la figura que se levanta en la escena.

VSM: ¿Qué papel juega en tus fotografías el pie de imagen?

PI: Mi intención la mayoría de las veces es que la fotografía per se transmita lo que deseo o me interesa proyectar, el pie de imagen lo empleo como un apoyo. Personalmente es más complejo expresarme de forma escrita, pero creo que muchas veces sirve como complemento a la imagen e incluso pueden tomar la misma importancia.

vsm: Cuando decides trabajar con series, ¿cómo preparas el proyecto y normalmente cuánto tiempo le dedicas?

PI: La naturaleza propia de cada proyecto es la que dicta su duración y el tiempo de planeación requerido. Los trabajos personales regularmente exigen más tiempo, como el proyecto que desarrollo actualmente, por ejemplo, el cual me ha llevado dos años completarlo debido a todo el trabajo de archivo y de investigación que he hecho. Cuando el trabajo viene por encargo de algún espacio o galería, dependo un poco más del tiempo que me asignan, que puede ser un mes o incluso más.

vsm: En la serie Sonetlumiere (2019) hay escenas de vida cotidiana donde, como bien dices en tu presentación, parece que la luz es la que realiza el encuadre y el color se vuelve protagonista. Imágenes cotidianas, que con las fotos uno se permite observar de otra manera, con otra atención. Sin embargo, el orden que les das a partir de su cromática construye un hilo visual y llaman a la contemplación, a detener la mirada de otra forma. ¿Qué nos puedes decir al respecto de esta serie? 


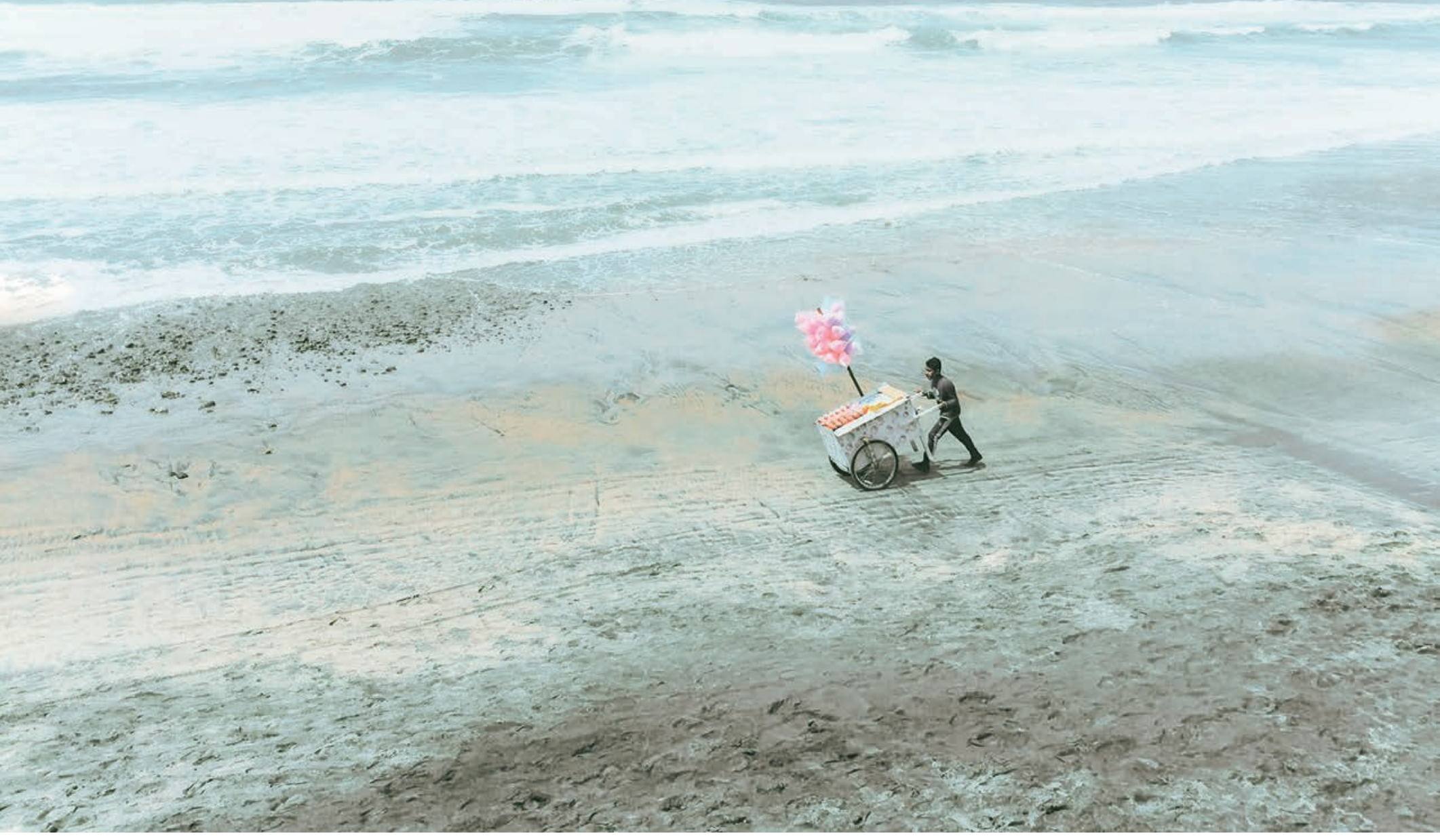

Figura 2. Paola Ismene, Daydream in Blue (2017). Fotografía digital. Fotografía ganadora del concurso "\#SelfExpression 2017" de la galería Saatchi de Londres y que formó parte de la exhibición "From Selfie to Self-Expression".

PI: La realicé para presentarla en la Galería Saatchi de Londres, la cual requería algunas especificaciones. La principal: tenía que realizarse enteramente con cámara de un teléfono celular, pues debía hablar de cómo la tecnología ha cambiado la forma en que vemos el mundo. Con esto en mente decidí fotografiar las escenas que veo diariamente inmersas en la cotidianidad, en las cuales, por un lado podía mostrar la ciudad donde vivo sin caer en lugares comunes, y por otro lado lograba reflejar la libertad que 


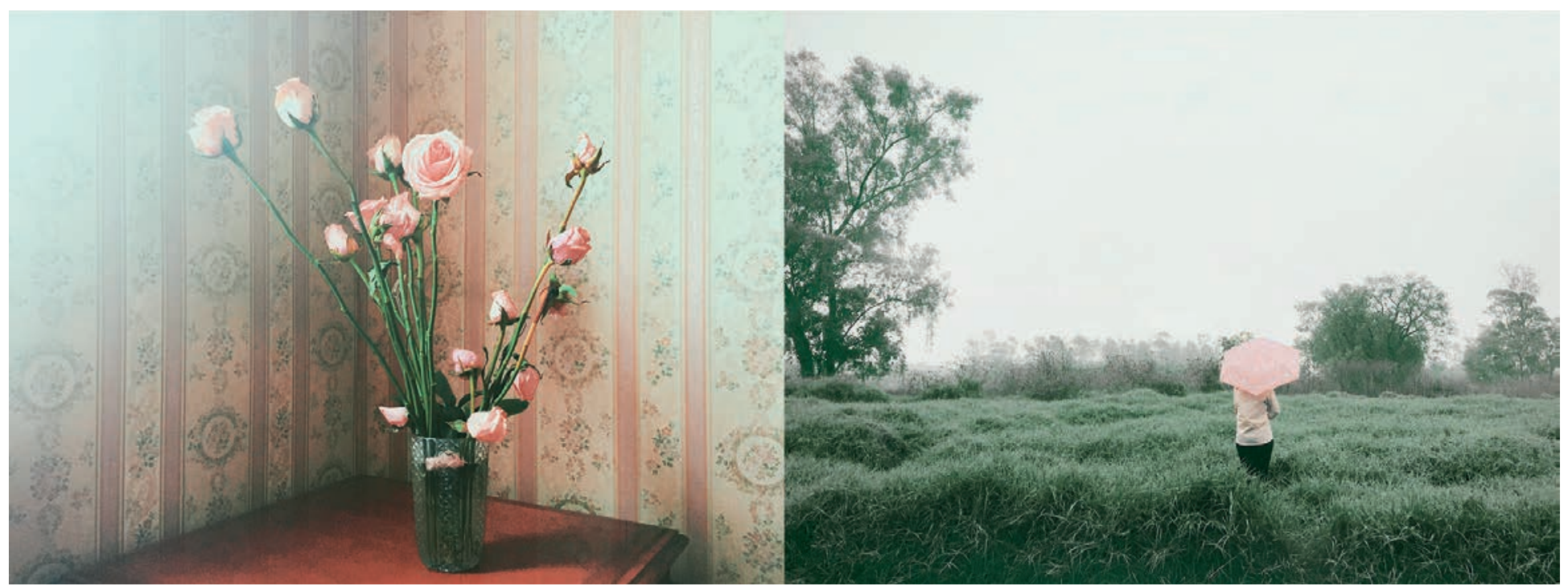

Figura 3. Paola Ismene, Un día más, un día menos (2017). Fotografía digital.

siento al transitar con una cámara de celular por espacios que gracias a la fotografía puedo capturar y a la vez pasar desapercibida.

vsm: ¿Cómo ha cambiado tu forma de construir imágenes, de pensar la fotografía a lo largo de tu carrera?

PI: Mi relación con la fotografía se ha ido modificando, claro. Al principio producía muchas más imágenes, todo era un poco más espontáneo y sin un objetivo claro o idea concreta en mente; no realizaba proyectos o series como tales. Con el paso del tiempo he aprendido a tomar los procesos más en serio, a pensar más en la imagen y su propósito, para así generar discursos más enfocados en el contenido que sólo imágenes técnicamente impresionantes y estéticamente atrayentes. Lo que personalmente debe permanecer y me motiva a seguir haciendo fotografía es el impulso creativo, y la intuición.

vsm: Al consultar tu cuenta en Instagram (@paolaismene), uno encuentra tu obra, pero también imágenes "sueltas" (que no forman parte de un proyecto), imágenes "en diálogo" (pares de imágenes), series de fotos y... 
Nierika 21 - Año 11 - enero-junio de 2022

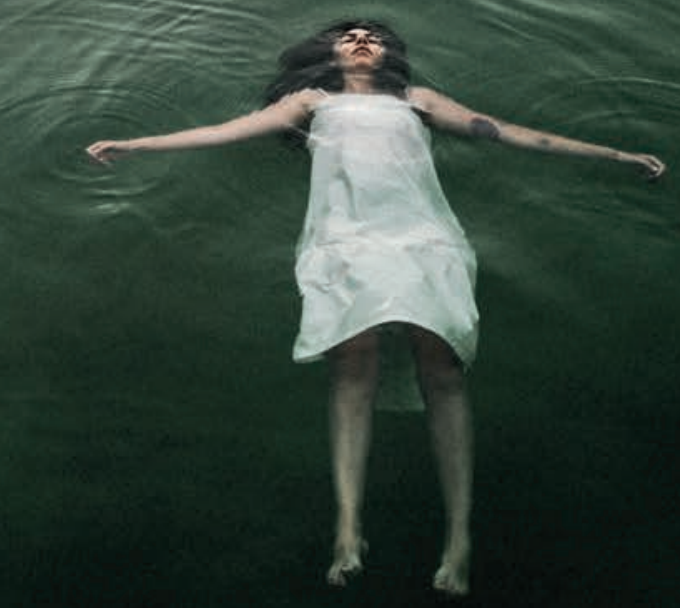

Figura 4. Paola Ismene, Génesis (2019). Fotografía digital. 
me parece que ahí te permites escribir más al momento de presentar tus imágenes. Pensando desde el punto de vista de su circulación, su puesta en común, ¿qué papel tiene para ti esta red social?

PI: Cuando comencé a usar Instagram lo hacía con fines de esparcimiento personal, para compartir cosas de mi vida privada con amigos y gente cercana, pero con el paso del tiempo, y la evolución misma de la red, comencé a profesionalizar la cuenta. Ahora trato de subir contenido más puntual sobre mis proyectos, bocetos o ideas sobre lo que estoy desarrollando en el momento. Creo que Instagram es una tribuna fundamental en la difusión de la obra de cualquier creador. Es por ahí donde muchas personas te contactan, a partir de tus publicaciones; es así que, en la actualidad, podría considerarlo más como un portafolio público de trabajo.

vsm: Tu obra ha sido exhibida en distintas galerías, en varios países. ¿Cómo ha sido tu experiencia con curadores? ¿Has podido incidir y seleccionar lo que se expone?

PI: Mi experiencia con las galerías ha sido bastante satisfactoria ya que nunca me he sentido limitada a expresar mis opiniones. Regularmente, los curadores tienen una idea preconcebida del trabajo que quieren seleccionar y dónde desean ubicarlo dentro de determinada exposición. Me parece muy enriquecedor observar la manera en que ellos van integrando las obras, la interpretación y la edición que hacen del material, ya que en muchas ocasiones me permite ver algo que yo no había contemplado. La mirada externa es fundamental para la retroalimentación del trabajo personal.

vSM: ¿En qué proyecto trabajas ahora?

PI: Actualmente trabajo en un proyecto titulado Sin lluvia nada crece, donde hablo sobre mi infancia y el vínculo materno. Ha sido bastante denso desarrollarlo, por las implicaciones personales que conlleva. Lo comencé en 2019 y este año lo retomé, después del caos de la pandemia. Ahora mismo me encuentro en la etapa final de edición de la obra. 


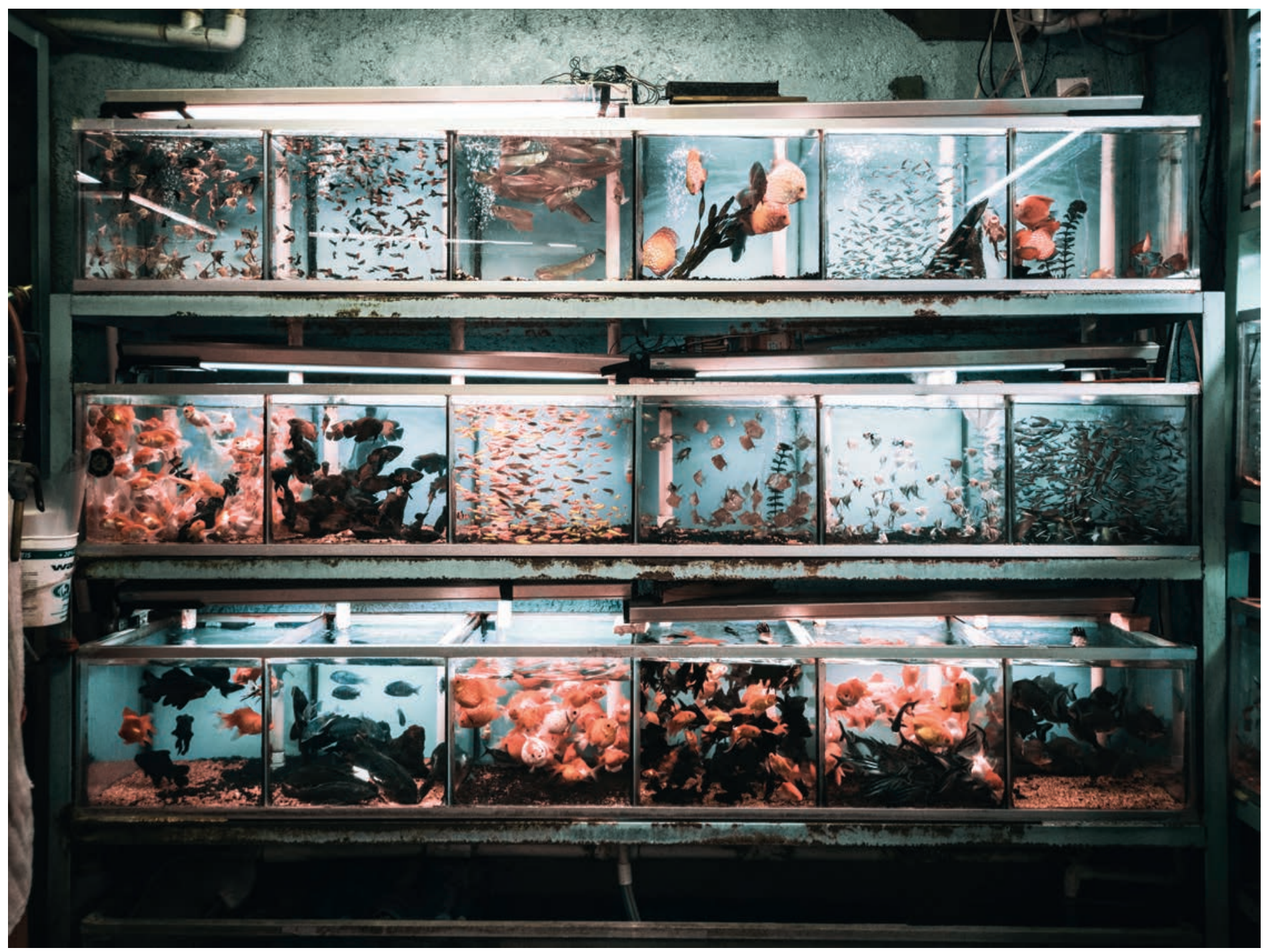

Figura 5. Paola Ismene, Mar adentro (2018). Fotografía digital.

vsm: Muchas gracias, Paola, por permitirme dar a conocer tu trabajo a nuestros lectores y compartir con ellos tu forma de pensar y crear. Espero que hayamos despertado su interés por ver el mundo desde tu mirada e inspiremos a otros a que capturen su entorno y podamos conocer otras formas de ver. 


\begin{abstract}
Paola Ismene
Nació en la ciudad de México. Realizó la licenciatura en Ciencias de la Comunicación en la Universidad Nacional Autónoma de México y la de Fotografía en la Escuela Activa de Fotografía. Ha continuado sus estudios en el Museo Universitario de Arte Contemporáneo y en Hydra + Fotografía, entre otros. Ha recibido varios premios, entre ellos fue finalista de la Beca Photo Taken 2020 de la Fundación Lucie y ganó el concurso "Selfexpression" de la Saatchi Gallery London en 2017.
\end{abstract}

\title{
Valeria Sánchez Michel
}

Doctora y maestra en Historia por El Colegio de México y licenciada en Historia por la Universidad Nacional Autónoma de México. Certificada por la Universidad de Harvard en Higher Education Teaching. Fue investigadora asociada a la Chaire Nycole Turmel sur les espaces publics et les innovations politiques, en la Universidad de Quebec en Montreal (2015). Ha realizado investigación histórica y tiene publicaciones sobre la formación de instituciones y la construcción de la Ciudad Universitaria de la UNAM. Ha escrito libros de texto para educación básica y es la coordinadora nacional de la Olimpiada Mexicana de la Historia (Academia Mexicana de Ciencias). Actualmente es coordinadora de la maestría en Estudios de Arte del Departamento de Arte de la Universidad Iberoamericana y es directora de la Revista Arte Ibero Nierika. 


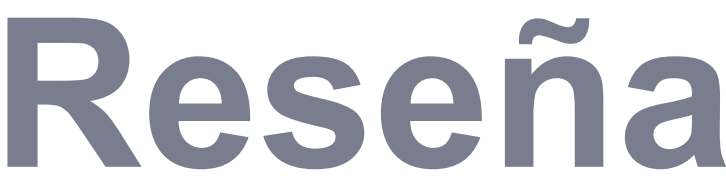

\section{Bienal de La Habana. Pautas para leer una exhibición que no se vio.}

\section{Blanca Victoria López Rodríguez \\ Universidad Iberoamericana Ciudad de México}

La XII edición de la Bienal de La Habana se desarrolló en dicha ciudad caribeña entre el 22 de mayo y el 22 de junio de 2015. Durante un mes el público pudo acceder y participar del resultado de los intensos procesos investigativos y creativos que, en el transcurso de tres años, su colectivo de $11 \mathrm{cu}-$ radores y sus más de 300 artistas invitados habían estado desarrollando.

Con el título Entre la Idea y la Experiencia la plataforma conceptual del evento mostraba un interés marcado por los proyectos colaborativos que propiciaran experiencias sociales, comunitarias y de investigación interdisciplinaria, y que ponderaran el proceso por encima del resultado objetual. Basado en ello, el encuentro propició el intercambio entre artistas, curadores, agentes culturales, científicos, médicos, campesinos, pedagogos, etcétera, dando lugar a la introducción del término "público específico". Éste hacía referencia a una audiencia cautiva que, al colaborar con los proyectos, era el principal auditorio al que estaban destinadas las propuestas artísticas acogidas por el evento.

Esta megaexposición se diseminó por toda la ciudad, incluyendo espacios barriales ubicados en el otro extremo de la Bahía de La Habana, donde nunca antes había llegado un proyecto cultural de tal envergadura. Heredera de una reputación de más de 35 años, dio seguimiento al legado de las anteriores presentaciones, al incluir en su nómina mayoritariamente a 
artistas de América Latina, el Caribe, África, Asia y Medio Oriente, regiones que - a los efectos de esta muestra-, fueron consideradas no desde una perspectiva geográfica, sino desde su condición de espacios de representación cultural diversa. Este último enfoque se erigió como uno de los cambios más significativos que introdujo el evento en su línea temporal, pues en esta oportunidad se hizo evidente el interés del equipo curatorial de desprenderse de algunas categorías ya en desuso, tales como "Tercer Mundo" y "Periferias culturales".

Este planteamiento - cuyos primeros indicios ya se avizoraban desde la edición anterior- se esgrimió como argumento principal para la diversificación de los proyectos invitados que, por primera vez en la historia del evento, incluían un número significativo de artistas europeos. Si bien muchos de ellos eran jóvenes, provenientes de países no considerados centros culturales, como Austria (Johann Lurf, Nikolaus Gansterer, Axel Stockburger), Noruega (Marte Johnslien, Ignas Krunglevicius), Portugal (Didier Faustino) o Suiza (Lang/Baumann), lo cierto es que la inclusión de estos países colocó sobre esta bienal más de una mirada sospechosa de quienes la consideraban como el evento de vanguardia de las artes (y los artistas) "olvidados". Las opiniones negativas al respecto se reforzaron con la inclusión en la lista de artistas consagrados como Daniel Buren, Michelangelo Pistoletto, Tino Sehgal, Gregor Schneider, Anri Sala, Joseph Kosuth, entre otros. A pesar de las suspicacias con que fue visto, la incorporación de estos creadores evidenció la voluntad por mostrar que la bienal — siendo en sí misma un suceso cultural susceptible de sufrir transformaciones- se realizaba para acercar el arte internacional de todos los niveles a los habitantes de la ciudad, convirtiéndolos en protagonistas indudables del evento.

Precisamente, el hecho de que la mayoría de las propuestas tuvieran un carácter colaborativo e interdisciplinar, y que éstas acontecieran fuera de los museos y galerías (universidades, laboratorios científicos, muelles, etcétera) puso de manifiesto un cuestionamiento a los procesos creativos del arte actual y al modelo mismo del evento bienal, en tanto colocaba en crisis 
roles fundamentales en el mundo del arte como los de megaexposición, autor, públicos, crítica e institución. Todos estos conceptos se encuentran actualmente en la mira de los estudios sobre arte contemporáneo y sus dinámicas, y cabría preguntarse cuántos de ellos fueron reformulados a partir de esta edición de la Bienal de La Habana.

A pesar de estar concebida como un todo, difícilmente podía recorrerse la exhibición en su totalidad, en tanto se trataba de procesos que acontecían y que muchas veces no dejaban más registro que los videos y fotografías que los espectadores hacían con sus teléfonos y, sobre todo, la experiencia de los participantes. Por ello, rápidamente fue llamada —incluso entre sus participantes-como la "Bienal Invisible", apelativo que, más allá de su surgimiento peyorativo, bien servía a los propósitos originarios del evento.

Baste mencionar como ejemplo de esa invisibilización la forma en la que se mostraron dos de las obras presentadas en el parque Trillo, una de las más de 40 sedes diseminadas por toda la ciudad. En los árboles del parque fueron instalados nidos para aves confeccionados con barro local, como parte del proyecto del artista argentino Adrián Villar Rojas. Estos nidos -que funcionaron además como señalización para cada espacio expositivo-, fueron el resultado de talleres con ornitólogos y artesanos, y estaban realizados de formas diferentes para acoger especies de aves locales y facilitarles un hábitat. Paralelamente, en los propios árboles se instalaron altavoces para el trabajo del artista sonoro sudafricano James Webb, con grabaciones de más de 15 especies de aves diferentes, ninguna de ellas endémica de Cuba. El resultado era una sensación de extrañamiento ante un trino desconocido que hacía que los transeúntes miraran a los árboles y sólo así pudieran apreciar los nidos, que también resaltaban por lo poco usuales. Resulta fundamental destacar el hecho de que ninguno de los dos trabajos estuvo particularmente señalizado: no se mencionaban los nombres de los autores, su procedencia ni se describía la pieza. Este tipo de relación establecida entre las obras (y sus creadores) no sólo mostraba el interés de los organizadores por hacer de la curaduría un ejercicio creativo conjunto entre comisarios, artistas y participantes, sino que abría una 
ventana a la apreciación de una perspectiva multisensorial de las artes contemporáneas que ha sido prácticamente inexplorada en los eventos de esta categoría.

A esta proposición de la apreciación sensorial se sumó la obra El olor de un extraño, del artista belga Peter de Cupere, que exploraba la dimensión olfativa como detonante de procesos apreciativos en el arte contemporáneo. Para desarrollarla se procesaron a nivel de laboratorio diferentes aromas (de esmog, de perfumes de flores, del sudor de varias personas, de la vagina de 49 mujeres, entre otros) y, a través de métodos de modificación genética y de ingeniería, se incorporaron las esencias a diferentes especies de plantas y flores. Así se buscaba generar una disonancia entre lo que el espectador veía y lo que olfateaba.

En esta misma dimensión de lo sensorial también se ubicó la propuesta de Anish Kapoor, la cual, al ritmo de la respiración grabada del artista, proyectaba colores específicos en la pantalla del cine Payret, uno de los más icónicos de la capital cubana. Con el cambio de color se transformaba visualmente el espacio, provocando en el espectador la inquieta sensación de que la sala se movía, de que ésta se reducía o se agrandaba. No se trataba únicamente de una experiencia visual, sino también espacial y de sensaciones de contraste entre lo que los ojos veían y lo que en realidad ocurría.

Otras obras de corte colaborativo aportaron a la idea de desmaterialización del arte, manejada como fundamento de esta megaexposición. Una de las más polémicas fue la propuesta del artista londinense Tino Sehgal, que reunió en una habitación a especialistas locales que se ofrecían a conversar sobre economía con el público asistente. A cambio de un buen argumento se les ofrecía a los participantes un peso cubano, la unidad monetaria mínima en el país. Para el espectador no avisado, nada especial sucedía en el espacio habilitado para esta obra en el Centro de Arte Contemporáneo Wifredo Lam. Allí sólo tenía lugar una discusión —a ratos acalorada- sobre economía y desarrollo sostenible, temas que, ade- 
más, se encuentran en la mira del debate público en ese país. Este tipo de propuestas no sólo respondía muy bien a los presupuestos teóricos que esgrimía el equipo curatorial, sino que se adaptaba estratégicamente a las condiciones de escasez de recursos económicos bajo las cuales se celebró esta megaexposición.

Mucho dio de que hablar, en su momento, la XII Bienal de La Habana, una edición para ser experimentada, olfateada, escuchada, trascendida. De hecho, otros eventos internacionales de mayor reconocimiento repitieron posteriormente algunos de los formatos que ésta introdujo como propuestas para cambiar el muy cuestionado Modelo Bienal. ${ }^{1}$ No obstante, quizás por esa propia condición de invisibilidad, el reconocimiento de los límites trascendidos, de los aportes realizados y, sobre todo, las respuestas a las preguntas que esta muestra colocó sobre la mesa no han sido, todavía hoy, suficientes. Sirva esta breve reseña como un intento de enunciar la actualidad de los presupuestos que en esa edición de la Bienal de La Habana fueron defendidos y, sobre todo, ojalá aporte algunas pautas para leer, una vez más, una exhibición que no se vio.

\section{Blanca Victoria López Rodríguez}

Curadora y crítica graduada en Historia del Arte por la Universidad de La Habana, ha trabajado como especialista en el Centro de Arte Contemporáneo Wifredo Lam y como miembro del equipo de curadores de La Bienal de La Habana. Colabora con diversas publicaciones, nacionales e internacionales, y como investigadora de arte contemporáneo ha sido invitada a impartir conferencias en la feria ARCO (Madrid), el Helsinki International Curatorial Programme (Finlandia) y la Universidad de Bellas Artes de Tama (Japón), entre otros. Actualmente cursa en México el programa de maestría en Estudios de Arte de la Universidad Iberoamericana.

\footnotetext{
1 Tal fue el caso de Documenta 14 (2017), dirigida por Adam Szymczyk, que repitió la idea desarrollada en la XII Bienal de La Habana de realizar una muestra audiovisual con materiales experimentales.
} 